Archivos de

Ciencias

Educación
Archivos de Ciencias de la Educación ISSN: 2346-8866

revistaarchivos@fahce.unlp.edu.ar

Universidad Nacional de La Plata Argentina

\title{
La idea de revolución en la Pedagogía del Oprimido
}

Fernández Mouján, Inés

La idea de revolución en la Pedagogía del Oprimido

Archivos de Ciencias de la Educación, vol. 13, núm. 16, 2019

Universidad Nacional de La Plata, Argentina

DOI: https://doi.org/10.24215/23468866e067

Atribución no comercial compartir igual (CC BY-NC-SA) 4.0 
Dossier: A 50 años de Pedagogía del Oprimido: lecturas en torno al legado de Paulo Freire

\title{
La idea de revolución en la Pedagogía del Oprimido
}

\author{
The idea of revolution in Pedagogy of Oppressed \\ Inés Fernández Mouján \\ Cátedra Abierta Paulo Freire, Universidad Nacional de \\ Mar del Plata, Argentina \\ imoujan@gmail.com
}

DOI: https://doi.org/10.24215/23468866e067

Recepción: 15 Agosto 2019

Aprobación: 30 Noviembre 2019

\section{ReSUMEN:}

Escribo estas líneas atravesada por la tristeza de momentos difíciles que nos impone el orden neoliberal/necrófilo, pero con la alegría que me provoca escribir sobre Pedagogía del Oprimido. Lo hago a partir de una lectura comprometida y rigurosa de la obra. Elijo analizar la idea de "revolución" considerando dos versiones de la obra: Pedagogia do Oprimido (o manuscrito), 2013 y Pedagogía del Oprimido, 1971. Focalizo en su contexto de producción y en la racionalidad revolucionaria presente en el ensayo a partir de: "Primeras Palabras", "Capítulo 1" y el "Capítulo 4". Entiendo que estos apartados, condensan las ideas principales del escrito. Indago en estas páginas: ¿A quiénes les escribe Paulo Freire? ¿Cuál es el contexto de producción de la obra? ¿Con quiénes dialoga? ¿Cuáles son sus preocupaciones? ¿Qué lugar ocupa la idea de "revolución” en Pedagogía del Oprimido?

Palabras Clave: Freire, Pedagogía del Oprimido, Contexto, Revolución.

\section{ABstract:}

I write these lines through the sadness of difficult moments that impel us the neoliberal/ necrophile order, but with the joy that causes me to write about Pedagogy of the Oppressed. I do so from a committed and rigorous lecture on the work. I elect to analyze the idea of "revolution" considering the versions of the work: Pedagogy of the Oppressed (the manuscript), 2013 and Pedagogy of the Oppressed, 1971. Focusing on its production and revolutionary rationality context present in the essay from: "First Words", "Chapter 4" and "Chapter 1". I understand that we are apart, condensing the main ideas of writing. I ask in these pages: Who does Paulo Freire write to? What is the context of the production of the work? What do you talk about? Who are your concerns? What place does the idea of "revolution in the Pedagogy of the Oppressed occupy?

KEYWORDS: Freire, Pedagogy of the Oppressed, Context, Revolution.

\section{La revolución es un sueño eterno}

(Andrés Rivera, 1987)

I.

Escribo estas líneas desde Argentina y atravesada por la tristeza de momentos difíciles que nos impone el orden neoliberal y necrófilo, pero con un sentimiento de enorme gratitud hacia Paulo Freire y con la alegría que me provoca escribir sobre su obra. Tengo la firme convicción de que lxs "no europexs" podemos pensar, apuesto al "inédito viable" 1 y la utopía de un mundo mejor para todxs.

Fui invitada ${ }^{2}$ a participar del homenaje a Paulo Freire a 50 años de la publicación de su obra más importante: Pedagogía del Oprimido. Mi intención es observar las inquietudes y las vicisitudes de un hombre con su escritura. Lo hago a partir de una lectura comprometida, y elijo analizar la idea de "revolución" presente en la obra (a partir de dos versiones de la obra ${ }^{3}$ ) Pedagogia do Oprimido (o manuscrito) de $2013^{4}$ y la otra, la $2^{\circ}$ edición de 1971 de Tierra Nueva. 
En el año 2017 llega a mis manos como regalo de Lutgardes Freire (hijo de Paulo Freire) la primera edición del manuscrito original ${ }^{5}$ de Pedagogía del Oprimido. La lectura de este en su idioma original, y de puño y letra del propio Freire despertó en mí una fuerte emoción. Con el transcurso de los días fui descubriendo que había referencias que no estaban consignadas en la edición montevideana la primer omisión que encontré fue la referencia a "Reforma o revolución" de Rosa Luxemburgo (1964). Esta falta me impulsó a (re)leer la obra tratando de identificar la importancia de la cita. Además de esta omisión, encontré otras en relación con Frantz Fanon y su obra Los Condenados de la Tierra $(1961)^{6}$. Sugiero a manera de hipótesis que estas omisiones pueden responder por un lado a la necesidad de Freire por editar la obra que había terminado de escribir tal como lo señala en las "Primeras palabras" del Manuscrito en "Santiago inverno de 67" (Freire, 2013, p. VII) pero que no puede editar en Chile: "Em 1968, receoso de que a obra fosse confiscada haviam surgido boatos de que forças da inteligência chilena estariam atrás de um livro "subversivo e perigoso" datilografou os manuscritos e tirou algumas cópias antes de entrega-los a Chonchol” (Romãoy Gadotti, 2018, p.7). Otra de mis hipótesis es que, ambos intelectuales son críticos de las estructuras político-burocráticas marxistas, y en el caso particular de Fanon, el martinico asume una postura anticolonial de sospecha del pensamiento europeo por la marca racial que éste comporta, lo que lo transforma en referencia ineludible de los movimientos revolucionarios poscoloniales que recorren América y el mundo ${ }^{7}$.

Ahora bien, al cabo de un tiempo estas inquietudes comenzaron a cobrar forma y darle sentido a lo que voy a analizar en este escrito, principalmente en la referencia a como Freire construye la idea de revolución, y su relación con la pedagogía y el diálogo con el pueblo. Entiendo que los términos: revolución, pedagogía y diálogo condensan sus anhelos, sus deseos, las ideas principales de su escrito y su compromiso con la urgencia política del contexto en el que produjo la obra. Tal como lo señala desde el inicio de la obra, es un ensayo dirigido a "hombres ${ }^{8}$ radicales en un proceso de liberación" (Freire, 1970, p. 30).

Organizan estas notas los siguientes interrogantes: ¿A quiénes les escribe? ¿Cuál es el contexto de producción de la obra? ¿Con quienes dialoga? ¿Cuáles son sus preocupaciones? ¿Qué lugar ocupa la idea de "revolución" en Pedagogía del Oprimido?

\section{El CONTEXTO DE PRODUCCIÓN DE UNA PEDAgOgía REVOLUCIONARIA}

Corre la mitad del siglo XX, luego de la segunda guerra mundial, la guerrilla se ha transformado en América Latina, el Caribe y África en lucha revolucionaria. Sus tácticas están fuertemente influenciadas por la izquierda radical en una crítica a la política soviética. Así podemos ubicar las luchas de Mayo del 68 en Francia, la Revolución Cultural de Mao Tse Tung de 1966-1976, la Revolución Cubana de 1959, la presencia del Che Guevara, la guerra revolucionaria de Argelia de 1954-1962, las luchas de liberación de las colonias portuguesas en África (Guinea Bissau, Cabo Verde, Tanzania, Mozambique) y el Movimiento de las Panteras Negras en EE. UU. Sumado a estos acontecimientos en Argentina a partir de 1961 germinan concepciones que van más allá de la resistencia para plantearse un proceso que tiene como protagonista central al peronismo revolucionario. Éste se plantea una política organizativa para transformar la sociedad y recuperar la experiencia política del peronismo de 1945-1955. Lo que se produce es un gran debate teóricometodológico cruzado por las revoluciones cubana y argelina, las posiciones insurreccionalistas y de guerra popular prolongada, el foco armado y la política de cuadros en el marco de la constitución de un movimiento de liberación nacional. En estos debates están las figuras centrales de Ben Bella, Frantz Fanon, el Che Guevara, John William Cooke y José Hernández Arregui (Duhalde y Pérez, 2003, p. 29).

Para esos años, en 1964 a consecuencia del golpe de estado contra el presidente João Goulart, Paulo Freire 9 deja su Recife natal ${ }^{10}$. Luego de tres meses de prisión sale al exilio pasa por Bolivia y llega a Santiago de Chile ese mismo año. En Chile gobierna la democracia cristiana, veamos cómo nos relata los primeros momentos del exilio: 
Santiago se había transformado en un espacio o en un gran contexto teórico-práctico donde los que llegaban de otros rincones de América Latina discutían con los nacionales y con los extranjeros que allí vivían lo que ocurría en Chile y también lo que ocurría en sus países. La efervescencia latinoamericana, la presencia cubana [...] testimonio de que el cambio era posible, las teorías guerrilleras, la "teoría del foco", la personalidad carismática extraordinaria. Camilo Torres [...] la capacidad de amar del Ernesto Guevara [...] es posible que Santiago en sí mismo haya sido en aquella época quizás el mejor centro de "enseñanza" y de conocimiento de América Latina. Aprendíamos de los análisis, de las reacciones, de la críticas hechas por colombianos, venezolanos, cubanos, mexicanos, bolivianos, argentinos, paraguayos, brasileños, chilenos, europeos (Freire, 1999, pp. 41-42).

$\mathrm{Al}$ poco tiempo de llegar a Chile, colaboró con Jacques Chonchol y trabajó activamente junto a Ernani María Fiori ${ }^{11}$ en el Instituto de Capacitación e Investigación sobre Reforma Agraria (ICIRA). Es a partir de allí que se suma al trabajo con "proletarios urbanos, campesinos y hombres de clase media" (Freire, 1971, p. 20). Tal como menciona Pedagogía del Oprimido, es el resultado de estas observaciones en sus años de su exilio en Santiago.

Como puede leerse en las afirmaciones sostenidas a lo largo de este ensayo el carácter de la obra está desposeído de dogmatismos y de devaneos intelectuales, más bien son una muestra clara de su compromiso político con los desposeídxs. La intención de Freire es interrogar las prácticas educativas, desplegar una filosofía y una práctica educativa que piensa y actúa con $1 x s$ oprimidxs ${ }^{12}$ y con quienes luchan con ellxs. Escribe y dedica esta obra a lxs "condenados de la tierra" y a lxs cuadros revolucionarixs, es decir, a todxs lxs que luchan junto con el pueblo. Su dedicatoria inicial es clara: "A los desharrapados del mundo a los que en ellos se descubren y, asi descubriéndose, con ellos sufren, pero, sobretodo con ellos luchan” (Freire, 1971, la cursiva es del original). Éste punto de partida es una afirmación al mismo tiempo que una invitación a interrogar los basamentos de la educación. Lo que nos propone es la necesidad de asumir que toda situación pedagógica es un encuentro dialógico, es una tarea de concientización que tiene como objeto la opresión y como objetivo la liberación; es decir, la superación de la conciencia dual para recorrer junto a otrxs el camino de la descolonización y su consecuente revolución.

¿Qué influencias marcan su obra en estos primeros tiempos de exilio? Observamos la presencia del existencialismo, la fenomenología y el marxismo. Con la filosofía de Friedrich Hegel y la de Karl Marx asume la crítica a la teología y a la enajenación política, social y económica; en Jean Paul Sartre encuentra algunas respuestas para establecer la relación entre "ser para sí" y "libertad". Con la teoría hegeliana de la dialéctica del amo y el esclavo analiza la idea de "libertad arriesgada" y lo articula con el concepto marxista de "alienación". Con los elementos que le provee los pensadores marxistas críticos (Fanon, Mao, el Che, Lukács, Kosik, Sartre, Goldman, Marcuse) va a realizar un exhaustivo análisis de la relación opresorx-oprimidx pero no desde una posición idealista sino cómo se constituye históricamente la conciencia dominada y su relación dialéctica con la conciencia dominadora en la estructura de dominación. Las lecturas políticas de inspiración marxista lo ayudan a comprender la complejidad de las dinámicas económicas y sociales que determinan las condiciones de la opresión. Suma al análisis de la subjetividad oprimida los aportes de la fenomenología, el existencialismo y el anticolonialismo (Fanon, Sartre, Memmi). Al respecto, plantea que es necesario que el oprimidx deje de ser pensadx y vividx por el opresor como un "objeto-cosa", que su presencia obligue al dominador a entender que el dominado es un sujeto (hombre, mujer, niño, niña). En la entrevista realizada por la Revista Vispera de enero de 1969 Freire refiere:

[...] cuando hablo de conciencia, para que quede claro que no tengo una posición idealista, estoy refiriéndome al hombre como un cuerpo consciente. El núcleo central intenta comprender el fenómeno de la introyección de la conciencia dominadora por la conciencia oprimida. De lo que resulta que ésta se constituye como una conciencia dual. Es ella y es la otra hospedada en ella (Freire, 1969, p. 18).

Se puede destacar aquí la clara influencia de las advertencias que Frantz Fanon y Albert Memmi realizan sobre la emergencia de identidades impuestas que generan la doble conciencia del sujeto colonial. Dice Fanon: "El colono hace la historia y sabe que la hace [...] el colonizado siempre se presume culpable [...] el colonizado 
es un perseguido que sueña permanentemente con transformarse en perseguidor" (1961, pp. 45-47). Este juicio, de algún modo, es una alerta sobre el riesgo que corre el oprimidx producto de su alienación en el opresor, y en consecuencia, su imposibilidad de ser, de asumirse tal cual es, oprimidx. Así lo expresa Freire: "[...] em certo momento de sua experiência existencial, os oprimidos assumam uma postura que chamamos de "aderência” ao opressor. Nestas circunstâncias, não chegam a "ad-mirá-lo" o que os levaria a objetivá-lo, a descobrí-lo, como diz Fanon, fora de si" (Freire, 2013, p. 6) ${ }^{13}$. Se deriva de esto la presencia de un límite existencial, la alienación en el otro. Que en tanto imposibilidad de ser para sí obtura toda posibilidad de liberación. El miedo a la libertad lleva al oprimidx a acomodarse y adaptarse a los engranajes de la estructura de dominación. El sujeto alienado prefiere la adaptación a la seguridad vital y rechaza la libertad arriesgada.

$\mathrm{Na}$ imersão em que se encontram, não chegam os oprimidos a ver claramente a "ordem" que serve aos opressores que, de certa forma, "vivem" neles. "Ordem" que, frustrando-os no seu atuar, muitas vezes os levam, como salientou Fanon, a exercer um tipo de violência horizontal com que agridem aos próprios companheiros oprimidos pelos motivos mais simples. É possível que, ao agirem assim, mais uma vez explicitem sua dualidade (Freire, 2013, p. 31). ${ }^{14}$

Lo que observa Freire es una conciencia colonizada, tal como se lo sugiere Albert Memmi, en Retrato de un colonizado (1969). En este escrito el tunecino realiza sendos análisis sobre la "conciencia colonizada. A partir de la idea de deshumanización la intención de Memmi es mostrar por un lado como el colonizador ha impuesto una imagen mítica del colonizado afín a sus intereses económicos, y por ello consolida la idea que el colonizado es perezoso y mal trazado. La idea es poner en evidencia que si el colonizado es vago él es trabajador y activo. Al mismo tiempo que le corresponde una salario bajo porque su rendimiento es mediocre. Esta acusación incluye a todos los colonizados, no importa qué lugar ocupan socialmente. Se trata de verdad sin discusión, de una "institución" por medio de la cual el colonizador instituye al colonizado como un "perezoso" (Memmi, 1969, p. 93). En la huella de Memmi Freire interpreta que esta situación que perdura hasta el momento que se toma conciencia de la situación de deshumanización, es decir cuando "descubren nítidamente al opresor" (Freire, 1971, p. 66). El pedagogo interpreta que el tomar conciencia de la deshumanización es un camino posible para la humanización y su consecuente liberación.

Con la intención de sostener la crítica al sistema opresor y a la invasión cultural con la que opera el colonialismo, Freire traslada esta matriz teórica a la educación para observar y proponer una pedagogía "con" lxs oprimidxs. "Educación como acción cultural liberadora que sea capaz de permitir que la conciencia oprimida extroyecte la conciencia opresora que en ella habita" (Freire, 1969, p. 18). En síntesis, el objetivo en esta obra es realizar unas consideraciones para "defender el carácter eminentemente pedagógico de la revolución” (Freire, 1971: 70). Una educación liberadora y revolucionaria que debe ser de "cointencionalidad", es decir, todxs somos sujetxs en el acto de develar la realidad, criticarla y en esta misma acción (re)crear el conocimiento.

\section{LA REVOLUCIÓN, RAZÓN REVOLUCIONARIA}

Interesa en este apartado ahondar en la idea de "revolución" ${ }^{15}$ y analizar(la) con la noción de "razón revolucionaria": acto dialógico de toma de conciencia y acción cultural liberadora. Ya en las "Primeras palabras" de la obra, Freire indica que su escrito es el resultado de tres años de exilio y que "la pedagogía del oprimido implica una tarea radical" (1971, p. 33). Por ello, dedica el libro a lxs hombres y mujeres radicales, preocupados por el problema de la humanización e interpelados por el sufrimiento de sus pueblos. Les propone una transformación pedagógica creadora, crítica y liberadora; una toma de conciencia que permita ir más allá del miedo a la libertad. El miedo a la libertad, del que, necesariamente no tiene conciencia quien lo padece, miedo que nos lleva a ver lo que no existe. "En el fondo, quien le teme a la libertad se refugia en la "seguridad vital", para usar la expresión de Hegel, prefiriéndola a la libertad arriesgada [...] solamente arriesgando la vida se mantiene la libertad (Freire, 1971, p. 28). 
Nos indica, también, la necesidad de interpelar la realidad concreta y objetiva, asumir una acción revolucionaria; un encuentro con el pueblo que articule pedagogía y revolución. Al mismo tiempo que nos convoca a asumir un compromiso con la causa del pueblo. A partir del cual, hace una crítica mordaz a la posición sectaria por sus posiciones de verbalismo reaccionario: "Verbalismo de quien se "pierde" hablando de vocación ontológica, amor, diálogo, humildad y simpatía." (Freire, 1971, p. 29), pero no se compromete con quienes sufren. Lxs sectarios por su fatalismo, su irracionalidad y su falsedad; por sentirse dueñxs del tiempo y del saber de lxs otrxs, y son "un obstáculo para la emancipación de los hombres" (Freire, 1971, p. 30). Realizada esta advertencia a ocho de la publicación de Pedagogía del Oprimido insiste con su preocupación inicial:

El papel de las clases oprimidas en el proceso de su liberación y las relaciones entre ellas y los liderazgos revolucionarios [...] La revolución es en sí un acto pedagógico, una pedagogía. es necesario que aquéllos que se comprometen con un proceso de transformación revolucionaria sean coherentes. La revolución no es algo para ser hecho por las masas, pero sí con ellas. Y si es con ellas, esta simple proposición ya sugiere una forma pedagógica dialógica a ser vivida y experimentada entre el liderazgo y las masas populares [...] Esta es una cuestión que los liderazgos se tienen que contestar en su praxis revolucionaria. Yo diría, sin embargo, que este intento de comunión con las masas se encuentra, a mi juicio -y lo dije en la Pedagogía del Oprimidomuy encarnado en Guevara y en Fidel (Freire, 1978, pp. 6-7).

En sintonía con lo antes señalado cita en el cierre de sus "Primeras palabras" una advertencia que nos hace Rosa Luxemburgo: "Enquanto o conhecimento teórico permaneça como privilégio de uns quantos acadêmicos dentro do Partido, êste se encontrará em grande perigo de ir ao fracasso" (Freire, 2013, p. VII) ${ }^{16}$. Mi interpretación es que Freire hace suyas las palabras de una mujer, que interpela a propios y ajenos, pero, principalmente a la dirigencia revolucionaria. Rosa Luxemburgo militante socialista, cofundadora del Partido Comunista Alemán, y cómo señala Jorn Schütrumpf (estudioso de su obra) la filósofa polaca fue una de las personas más extraordinarias de la izquierda europea: "Una mujer que rechazaba privilegios por el hecho de ser mujer, porque sabía que este tipo de comportamiento estaba dirigido únicamente a la negativa legítima de igualdad de derechos" (Schütrumpf, 2015, p. 22). Una mujer que junto con otrxs intelectuales extremó la coherencia entre palabra y acción, del mismo modo que Fanon, Guevara y Gramsci, se mantuvo fiel un pensamiento independiente, que no se sometió a ninguna doctrina, ni verdad revelada, igualdad, solidaridad y libertad en un mismo plano ninguna subordinada a la otra. "Mordaz" e irónica, y en la discusión política “impiadosa”. Entendió que la organización se formaba gracias a la acción revolucionaria. Por ello sostuvo que la acción precede a la organización. Desde allí criticó al "marxismo oficial” al que lo diferenció del "marxismo verdadero no falsificado", aquel que propone "[...] la abolición de toda forma de opresión y explotación” (Schütrumpf, 2015, pp. 33-49).

En sintonía con la radicalidad de Rosa Luxemburgo, Freire en esta obra toma posición frente a lxs sectarios, a lxs reaccionarixs y a lxs espontaneístas y en esta zaga de crítica radical suma la sospecha al colonialismo que emprende Frantz Fanon. Con Fanon, Freire disloca las certezas sobre el humanismo, desconfía del legado moderno a partir de su crítica al colonialismo y a la posibilidad de una revolución en estrecha vinculación con la cultura nacional: "Liberación nacional, renacimiento nacional, restitución de la nación al pueblo" (Fanon, 1974, p. 30), para iniciar desde allí un proceso de reconocimiento entre sujetos colonizados. Se hace eco de su llamado a una "descolonización" 17 que en tanto política de emancipación "se propone cambiar el orden del mundo es, como se ve, un programa de desorden absoluto" (Fanon, 1974, p. 30). Fanon le muestra sin tapujos a Freire la naturaleza bárbara, tiránica, inmoral y deshumanizadora del sistema colonial; lo invita a demoler los argumentos sobre la llamada misión civilizadora y humanizadora. El Maestro hace suyas la política que el martinico plantea en Los Condenados de la Tierra y que en Sociología de una Revolución ${ }^{18}$ (1976), sostiene en términos pedagógicos: "A la pedagogía revolucionaria de la lucha de Liberación, debe seguir normalmente una pedagogía revolucionaria de construcción de la Nación” (Fanon, 1976, p. 76). Un proceso posrevolucionario que, para Freire, va a permitir expulsar de la conciencia oprimida la cultura opresora y encarar una "descolonización de las mentes" como indica Amílcar Cabral ${ }^{19}$. Acción cultural liberadora que 
es acción revolucionaria, acto pedagógico y gran tarea humanista e histórica de los pueblos oprimidos. Mi opinión es que este punto resulta clave en la obra, pues Freire brega por la toma de conciencia de la situación de deshumanización en que se encuentran los pueblos oprimidos. Deshumanización que debe ser criticada para luego transitar una subjetividad política que sea capaz de revolucionar y de dar vuelta lo impuesto, la opresión y la alienación para junto a otrxs transformar la injusticia social. Pensar la revolución, y una pedagogía en estos términos es un gesto que disloca lo instituido. En sintonía con George Lukács, entiende que no solo es necesario la continuidad de las experiencias revolucionarias, sino que hay que activar el desarrollo de experiencias revolucionarias. Hay que trabajar junto con el pueblo, con los oprimidos, transitar el camino de la concientización, sostener una acción-reflexión que permita la crítica y la acción transformadora de la realidad (Freire, 1971, p. 71).

Resulta, entonces, necesario rescatar su posición respecto a la revolución para territorializar su pensamiento en las tramas de la modernidad y ubicar su intertextualidad en una teoría o razón revolucionaria. Porque Freire ha tomado consciencia de la violencia del colonialismo y encuentra en la revolución la única solución a un problema irresoluble. Para el pernambucano toda relación de dominación, de explotación, de opresión ya es en sí violencia. No importa que se haga a través de medios drásticos o no. Es, a un tiempo, desamor y un impedimento para el amor. Obstáculo para el amor en la medida en que el dominador y dominado, deshumanizándose el primero por exceso y el segundo por falta de poder, se transforman en cosas.

[...] cuando el oprimido se rebela legítimamente contra el opresor, en quien identifica la opresión, se le califica de violento, bárbaro, inhumano, frío. Es que entre los incontables derechos que se adjudica para sí la conciencia dominadora incluye el de definir la violencia, caracterizarla, localizarla (Freire, 1973, pp. 41-42).

Mi punto de vista es que Freire acuerda con la crítica de Fanon "el gesto prometeico de Fanon, por medio del cual les roba el fuego a los dioses (y) sabe de sus consecuencias” (De Oto, 2003, p. 75), por ello insiste en una salida posible a la violencia del opresor. En este sentido, la revolución que nos plantea está ligada a la idea de transformaciones políticas en sintonía con las urgencias. Freire es un sujeto interpelado por el trágico descubrimiento de la deshumanización, provocada por la violencia colonial, siente la necesidad de asumir el problema de la deshumanización-humanización como una preocupación ineludible (Freire, 1971, p. 35). Este malestar lo traduce en una pedagogía revolucionaria que, animada por una auténtica generosidad, toma conciencia de que la práctica de esta educación conlleva la toma del poder político.

Se pregunta Freire: “¿Cómo realizar entonces, la pedagogía del oprimido antes de la revolución?” (Freire, 1971, p. 53). Sin duda, nos indica Freire, ésta tendrá dos momentos distintos e interrelacionados. Un primer momento en que la tarea es el descubrimiento del mundo de la opresión/alienación y el compromiso con una praxis de transformación; un segundo momento de permanente expulsión de los mitos de la estructura opresora para crear y sostener “[...] una pedagogía de los hombres en proceso de permanente liberación” (p. 54); una constante revisión crítica de la violencia y de su conciencia dual. Pues como le alerta Fanon: "El colonizado no deja de liberarse entre las 9 de la noche y las 6 de la mañana. Esa agresividad manifestada en sus músculos va manifestarla el colonizado primero contra los suyos" (Frantz Fanon, 1965 en Freire, 1971, p.64). De ahí que, advierte: "La revolución en la medida en que es liberadora, tiene un carácter pedagógico que no puede olvidarse a riesgo de no ser revolución" (Freire, 1971, p. 177).

En este sentido, para Freire, es nodal el ejercicio dialógico en una acción-reflexión permanente, porque para hacer la revolución no basta con comunicados que proclaman principios y acciones, para luego con la "toma del poder" desarrollar el esfuerzo educativo liberador. Hay quienes creen, dice Freire, en la necesidad de una educación liberadora pero proclaman que no es posible sostenerla antes del acceso al poder. Con esta actitud niegan el carácter pedagógico de la revolución que es acción dialógica y cultural, en tanto paso previo para transformarse en revolución cultural ${ }^{20}$. De modo que, para el pernambucano no hay dicotomía entre diálogo y acción revolucionaria, la idea de revolución está en estrecha relación con el diálogo. El diálogo es la esencia de la acción revolucionaria por ello propone una "teoría de la acción revolucionaria" en contraposición a 
la "teoría de la acción opresora". En la acción revolucionaria los participantes del diálogo son lxs hombres y mujeres del pueblo que junto con lxs líderes revolucionarixs intersubjetivamente inciden sobre el objeto mediador que es la realidad; tienen como "objeto la opresión” y como "objetivo su transformación", es decir, "la humanización de los hombres" (Freire, 1971, p. 176). Contrariamente a la acción revolucionaria (a esta pedagogía de la liberación) Freire ubica "teoría de la acción opresora" cuya esencia es antidialógica, en ésta los actores-sujetos opresores tienen como objeto de su acción a lxs oprimidos y la realidad, y como objetivo el mantenimiento de la opresión y de la realidad opresora (Ibíd). Estas ideas se sintetizan en el diagrama de la página 176 de Pedagogía del Oprimido (esquema que solo puede leerse en las distintas ediciones de Tierra Nueva-Siglo XXI, y en el manuscrito original, pero que fue omitido en las publicaciones en inglés y en portugués.

Imagen 1. Diagrama en su versión manuscrita de Paulo Freire (Freire, 2018, p. 322)

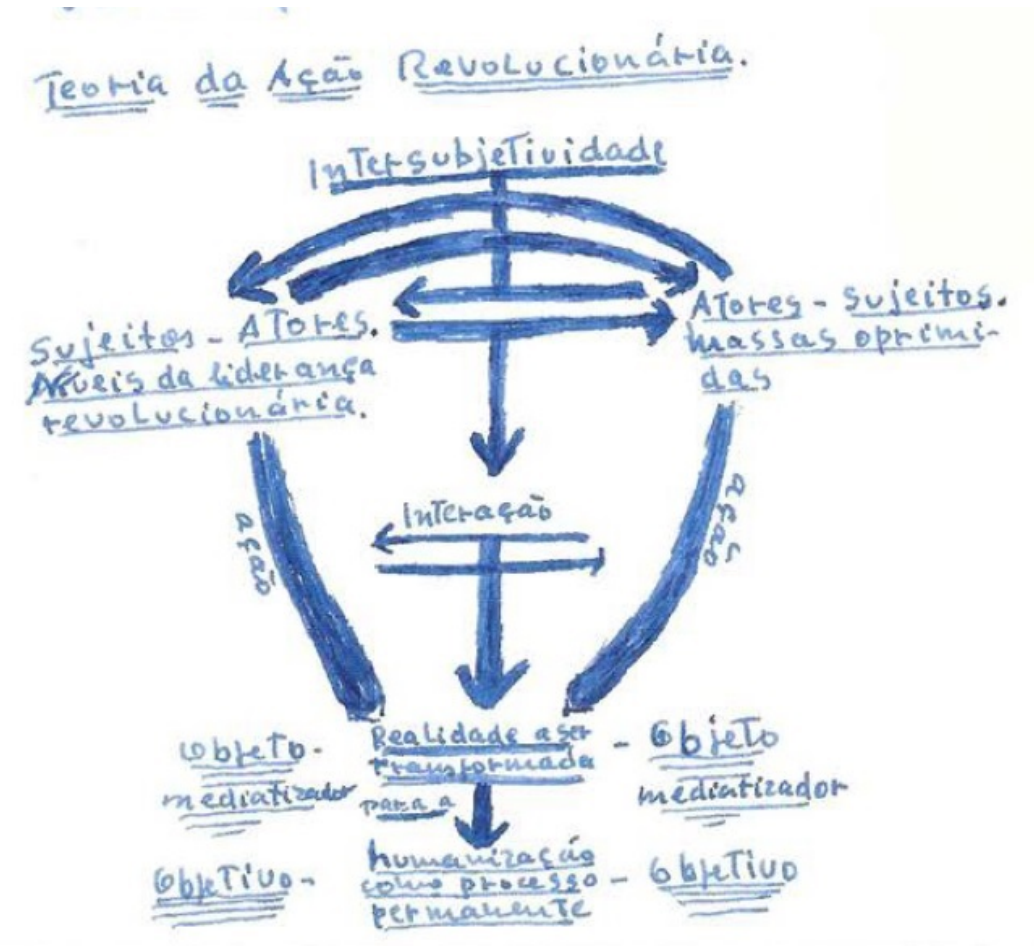

Teotia da Acáo opressora.

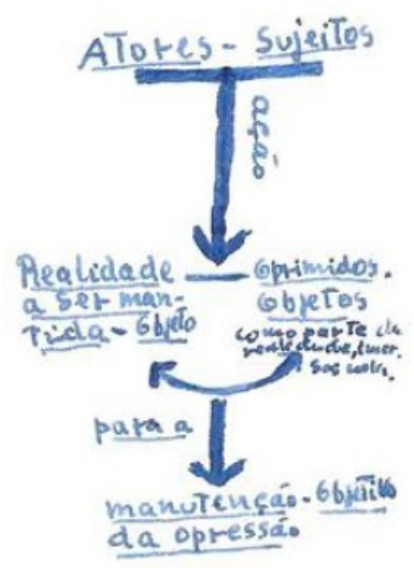


Imagen 2. Transcripción al español del diagrama

TEORÍA DE LA ACJIÓN REVOLUCIONARIA Intersubjetividad

$\begin{array}{ll}\begin{array}{l}\text { Sujetos - Actores } \\ \text { Niveles del liderazgo }\end{array} & \text { Actores - Sujetos } \\ \text { revolucionario } & \text { Masas oprimidas }\end{array}$

\begin{tabular}{|c|c|c|c|c|}
\hline \multicolumn{3}{|c|}{ Interacción } & $\begin{array}{l}\text { Realidad } \\
\text { que debe } \\
\text { ser mantenida } \\
\text { objeto }\end{array}$ & $\begin{array}{l}\text { Oprimidos. } \\
\text { Objetos } \\
\text { como parte de la } \\
\text { realidad, inmersos }\end{array}$ \\
\hline & REALIDAD & & & \\
\hline OBJETO & QUE DEBE & OBJETO & & \\
\hline MEDIADOR & $\begin{array}{l}\text { SER TRANSFORMADA } \\
\text { para la }\end{array}$ & MEDLADOR & para el & \\
\hline OBJETTVO & $\begin{array}{l}\text { Liberación } \\
\text { como proceso } \\
\text { permanente }\end{array}$ & OBJETIVO & $\begin{array}{l}\text { ma } \\
\text { de }\end{array}$ & $\begin{array}{l}\text { nimiento - objetivo } \\
\text { presión }\end{array}$ \\
\hline
\end{tabular}

TEORÍA DE LA ACCIÓN OPRESORA

Actores - Sujetos

En el diagrama de los tramos finales de la obra Freire resume gráficamente los principios fundamentales de su obra y recupera dialécticamente todo el planteo realizado y su posición respecto a una praxis educativa revolucionaria, acción-reflexión que debe involucrar al "liderazgo revolucionario, científico y humanista” (Freire, 1970,p. 177). Un liderazgo revolucionario que debe dialogar permanentemente con el pueblo, articular el conocimiento popular con el conocimiento crítico del liderazgo para así construir un nuevo conocimiento que se transforme en "razón de la realidad" (Ibíd), a través de una pedagogía liberadora, dicho de otro modo, una acción dialógica revolucionaria sobre el mundo social para transformarlo. Para Freire, la revolución exige personas críticas y conscientes de su papel de sujetxs históricos capaces de transformar y (re)crear el mundo. Esta teoría-acción dialógica que "busca la superación de la situación opresora conjuntamente con la instauración de una sociedad de hombres en permanente proceso de liberación" (Freire, 1971,p. 178). Aquí volvemos a observar como es el diálogo la condición necesaria para materializar la relación pueblo-liderazgo revolucionario. Así, hacia el final del ensayo concluye que: "el pueblo, en tanto aplastado y oprimido, introyectando al opresor, no puede solo construir la teoría de la acción liberadora. Sólo en el encuentro de éste con el liderazgo revolucionario, en la comunión de ambos, se constituye la teoría" (1971, p. 243).

La interpretación de José Romão (2012) es que Freire propone una idea de revolución como un cambio estructural de la realidad y de las representaciones del mundo; una transformación ontológica, gnoseológica y epistemológica. "É claro, porém, que uma transformação de estruturas econômicas, políticas sociais, a revolução do conhecimento e a epistemologia (teoria do ser), da gnoseologia (produção do conhecimento) e da epistemologia (teoria do conhecimento)" (Romão, 2012, p. 16). Exigencias de una racionalidad que se propone ir más allá de lo individual para realizar una creación colectiva, es decir lo que observamos, es 
una razón revolucionaria freireana transindividual y colectiva. Lo que Romão sugiere es que lo emergente en Freire es una razón revolucionaria, que sea superadora de la racionalidad que se encuentra atravesada por la colonialidad ${ }^{21}$. La exigencia ético-política es una liberación que asuma la descolonización de las mentes (2012, p. 15).

Cabría preguntarnos, entonces, del mismo modo que lo hace Romão, ¿Qué implica la razón revolucionaria en Freire? Para Freire, solo lxs oprimidxs pueden desenvolver esta razón revolucionaria, por su lugar que ocupa en el mundo. Sólo ellxs pueden preguntarse por su deshumanización y por la comprensión de la necesidad de la liberación. Es el oprimidx quien mejor puede entender el significado terrible de la sociedad opresora pues lo vive cotidianamente en su cuerpo y en su mente. Es en la praxis de la búsqueda de la liberación, en el conocimiento y en el reconocimiento de la situación de opresión que es posible la toma de conciencia crítica necesaria para la revolución. Acción-reflexión que solo puede ser alcanzada mediante la articulación entre la acción militante y el esfuerzo teórico. Lo que hay en la teoría freireana es una razón revolucionaria que se propone ir más allá de lo individual para realizar una creación colectiva, es decir, una razón revolucionaria transindividual y colectiva. En sintonía con Lukács asume la idea de una razón revolucionaria que en tanto praxis se torna revolucionaria cuando ella no puede abandonar la exigencia de crear colectivamente un nuevo orden económico, político, social y cultural, pero siempre a partir de establecer una relación dialéctica (de superación) en la que las situaciones límites se tornan inéditos viables (Romão, 2012, p. 22). Para Freire una razón se torna revolucionaria cuando asume un "compromiso incondicional" con la democracia cognitiva, en el sentido, del "reconocimiento de todos los saberes desarrollados por todas las formaciones y por todos los grupos sociales, principalmente, por las formaciones y por los grupos oprimidos" (Romão, 2012, p. 23). En virtud de ello, la idea de revolución o de razón revolucionaria freireana, para Romão, es un acto de superación, como relación dialéctica de contrarios y una praxis histórica. Es decir, no hay un ser individual en el centro de la escena sino un ser social que supera lo instituido, que enfrenta desafíos como posibilidad de inéditos viables y no como imposibles. Dice Romão que, la acción política que nos propone Freire está en función de la liberación de lxs oprimidxs, en tanto que, sujeto colectivo es el único capaz de transformaciones profundas del "coloniaje". El pueblo no se libera de las referencias teóricas de su colonizador sino se retiran todos los resquicios de la "Razón Colonial" (Romão, 2012, p. 41). Dicho de otro modo, para Freire la revolución cultural es el resultado de un proceso de liberación de las personas, de las clases sociales y de los pueblos que toman conciencia de su "razón oprimida". Praxis dialógica que incluye un proceso permanente de concientización y de revolución, y, una crítica a la racionalidad instrumental atravesada por la colonialidad (Romão, 2012, pp. 42-45).

\section{IV.}

Estas fértiles reflexiones de Pedagogía del Oprimido están dirigidas a lxs líderes revolucionarixs, a la formación de cuadros políticos, a lxs militantes políticos, a lxs hombres y mujeres radicales del pueblo que desafían y resisten las prácticas de dominación, de invasión cultural y de educación bancaria. La pedagogía del oprimido es una necesidad, es un discurso que interroga la educación repetidora de "verbalismo alienado y alienante" (Freire, 1971, p. 75) que propone nos propone una educación como acción cultural liberadora que se despliegue en una práctica histórica permanente, es decir una pedagogía revolucionaria. Así lo expresa Freire, en su carta de aceptación a la invitación del Consejo Mundial de Iglesias en 1970: "Ustedes deben saber que tomé una decisión. Mi problema es el problema de los desharrapados de la Tierra. Ustedes deben saber que opté por la revolución" (Freire en Gadotti y Torres, 1996, p. 141).

Finalmente. Creo que hay un antes y un después de la publicación de Pedagogía del Oprimido en el campo de la educación popular; porque es una obra que: nos obliga a (re)pensar(nos), nos ayuda a (re)definir nuestras teorías-prácticas educativas, y nos abre una línea de fuga interesante para seguir(nos) pensando y practicando una educación crítica de la racionalidad colonial. 
Con su corazón enorme y su razón revolucionaria, el Maestro pernambucano nos convida a practicar un ejercicio creador de la potencia del ser, una apuesta al funcionamiento de una maquinaria revolucionaria y creativa en tiempos regidos por el mercado. Su pedagogía del oprimido es una apuesta a lo desconocido, a una posición por el deseo de actuar contra la opresión y la colonialidad para cuestionar al conjunto de un sistema capitalista que se presenta cada día más injusto. Sus palabras finales son elocuentes:

"Si nada queda de estas páginas, esperemos que por lo menos algo permanezca: nuestra confianza en el pueblo. Nuestra fe en los hombres y en la creación de un mundo en el que sea menos difícil amar" (Freire, 1971, p. 243) 22.

\section{REFERENCIAS}

Cooke, W. (2014). Peronismo y revolución: peronismo y revolución. Apuntes para la militancia. La lucha por la liberación nacional/Informe a las bases. En Duhalde E. (comp). Obras Completas de John William Cooke. Buenos Aires: Colihue.

Duhalde, E. L. y Pérez, E. (2003). De Taco Ralo a la alternativa independiente. Historia documental de las Fuerzas Armadas Peronistas y del Peronismo de Base. La Plata: De la Campana.

Fanon, F. (1976 [1959]) Sociología de una revolución. México: ERA.

Fanon, F. (1973 [1961]). Los Condenados de la Tierra. Buenos Aires: Fondo de Cultura Económica.

Freire, P. (1969). Paulo Freire, entrevista. Revista Vispera, 3(10), 23-28.

Freire, P. (1971[1970]). Pedagogía del Oprimido. Montevideo: Tierra Nueva.

Freire, P. (1973 [1967]). La educación como práctica de la libertad. Buenos Aires: Siglo XXI.

Freire, P. (1996 [1992]) Pedagogía de la esperanza. México: Siglo XXI.

Freire, P. (2013). Pedagogía do Oprimido (o manuscrito), organizado por José Eustaquio Romão, Moacir Gadotti y Jason Ferreira Mafra. São Paulo: Ed, L, UNINOVE y Ministerio de Educação do Brasil

reire, P. (2018). Pedagogía do Oprimido (o manuscrito), organizado por José Eustaquio Romão, Moacir Gadotti y Jason Ferreira Mafra. São Paulo: Ed, L, UNINOVE y Ministerio de Educação do Brasil

Gadotti, M. y Torres C. (comp.). (2001). Paulo Freire. Una biobliografia. Buenos Aires: Siglo XXI.

Hobsbawm, E. (2017). Viva la Revolución. A era das utopias na América Latina. São Paulo: Companhia das Letras.

Karmentxu, M. (20 de mayo de 1978). Paulo Freire: "La educación es siempre un quehacer político". Diario El País. Recuperado de: https://elpais.com/diario/1978/05/20/sociedad/264463223_850215.html

Romão, J. E. (2012). Paulo Freire e Amílcar Cabral. Razões Revolucionárias e a descolonização das mentes. En Romão, J. E. e Gadotti, M., Paulo Freire e Amilcar Cabral. Razóes Revolucionárias e a descolonização das mentes (pp. 13-59). São Paulo: Ed. L.

Romão, J.E. y Gadotti, M. (2018). Prefácio à segunda edição dos manuscritos de Pedagogia do oprimido. História dos manuscritos e de sua obra”. En Ferreira Mafra, J., Romão J.E., Gadotti, M., Pedagogia do Oprimido ( $O$ Manuscrito). Sao Paulo: Ed, L Instituto Paulo Freire.

Schütrumpt, J. (Org.) (2015). Rosa Luxemburgo ou preco da liberdade. São Paulo: Fundação Rosa Luxemburgo.

\section{Notas}

1 Expresión que Freire utiliza para significar que su planteo lejos está de idealismos y voluntarismos, que es un pensamiento que resulta una apuesta a lo posible. "Sin un mínimo de esperanza no podemos ni siquiera comenzar el embate, pero sin el embate la esperanza, como necesidad ontológica, se desordena, se tuerce y se convierte en desesperanza que a veces se alarga en trágica desesperación" (Freire, 1996, p.19).

2 Agradezco especialmente a Federico Brugaleta, joven investigador del CONICET, con quien hace ya unos años estamos compartiendo ideas e investigaciones relativas a la obra de Paulo Freire.

3 Tomo esta decisión porque en sus lecturas hemos encontrado en la edición al español (y en portugués) omisiones que considero son muy importantes para los fundamentos de la obra. 
4 Actualmente hay dos versiones: en papel de 2013, y de 2018 versión digital con comentarios y versión mecanografiada. Como indican sus biógrafos José Romão y Moacir Gadotti: "Paulo Freire escrevia suas obras à mão. ele afirma que foi no contexto da efervescência latino-americana dos anos 60 que ele escreveu esse livro" (2018, p. 8).

5 El manuscrito original es resguardado por largos años de exilio por Jacques Chonchol, Director del Instituto Nacional de Desarrollo Agropecuario (INDAP) a quien Paulo Freire en 1968 le deja el manuscrito original junto con una carta de agradecimiento por la hospitalidad recibida en su llegada y exilio en Chile. Treinta y tres años después en 2001 cuando Chonchol participaba del Foro Social Mundial en Porto Alegre, Lutgardes Freire, José Eustaquio Romão y Moacir Gadotti iniciaron las primeras conversaciones para tener acceso al manuscrito que aún se encontraba en manos del exministro. Ese mismo año se los entrega, queda a resguardo en el Instituto Paulo Freire, y años más tarde, en el 2013 se publica como Pedagogía do Oprimido (o manuscrito) (Ferreira Mafra, Romão y Gadotti, 2018, p. 4)

6 Según se desprende de las citas del Manuscrito Freire ha leído a Fanon en español.

7 Esta hipótesis se desarrolla en profundidad en Fernández Mouján, I. "La huella de Fanon en el discurso freireano”. Revista do Estudios AntiUtilitaristas e Poscoloniais, Vol.1, N 01, Jan-Jun 2011.

8 Y también a "mujeres”. Respecto a la uso exclusivo del masculino en Pedagogía de la Esperanza ante la interpelación de las mujeres que lo leen reconoce la omisión del género femenino y el uso universal del masculino como un error de su parte. "En cierto momento de mis tentativas, puramente ideológicas, de justificar ante mí mismo el lenguaje machista que usaba, percibí la mentira o la ocultación de la verdad que había en la afirmación: "Cuando digo hombre, la mujer está incluida" (1999: 63).

9 Freire refiere a su historia personal en la entrevista realizada por Methol Ferré, periodista uruguayo de la Revista $V i s p e r a$ de enero de 1969, en el marco de la Conferencia Anual del CICOP, que tuvo lugar en Nueva York. "Fui un niño de la clase media que sufrió el impacto de la crisis del 29 y que tuvo hambre -recuerda Paulo Freire casi con alegría, como si esa circunstancia le hubiera cargado de potencias aún mayores para comunicarse con el pueblo, conocerlo, conocerse mejor y actuar juntos-. Yo sé lo que es no comer, no sólo cualitativa sino cuantitativamente. Pesqué en ríos, robé frutas en frutales ajenos. Fui una especie de niño colectivo, mediatizador entre los niños de mi clase y los de los obreros. Recibí el testimonio cristiano de mis padres, me empapé de vida y existencia, entendí a los hombres desde los niños (Freire en Revista Vispera, 1969).

10 Capital del empobrecido Nordeste brasileño, una vasta región, tierra de "bandidos sociales" y campesinos revolucionarios. Para esos años habitan en la ciudad de Recife 800 mil personas la mitad de ellxs viven en favelas (exesclavxs de caña de azúcar y algodón, pequeños campesinxs del sertao) que en su mayoría son analfabetxs (Hosbawm, 1970).

11 Exiliado brasileño en Chile amigo y colega de trabajo en el ICIRA, es el que prologa las primeras ediciones de Pedagogía del Oprimido.

12 Pobres, excluidxs, sin techo, analfabetxs, "condenadxs de la tierra”, desharrapadxs, distintos nombres para la alteridad negada.

13 He decidido tomar la cita del Manuscrito pues en la edición de Tierra Nueva la referencia a Fanon ha sido omitida. Veamos: “[...] en cierto momento de su experiencia existencial, los oprimidos asumen una postura que llamamos de "adherencia" al opresor. En estas circunstancias no llegan a "admirar-lo", lo que los llevaría a objetivarlo, a descubrirlo fuera de sí.” (Freire, 1971, p. 41, el entrecomillado es del original)

14 Esta cita del Manuscrito también difiere en la edición en español por un lado porque no se nombra a Fanon en el texto y luego en el pie de página se agrega una cita de Los Condenados de la Tierra que en el original no se encuentra: "El colonizado no deja de liberarse entre las 9 de la noche y las 6 de la mañana. Esa agresividad manifiesta en sus músculos va manifestarla el colonizado primero contra los suyos, Fanon, Frantz, Los Condenados de la Tierra, Fondo de Cultura, México, 1965, pág. 46." (Freire, 1971, p. 63).

15 Del tardío revolutio, -ōnis. 1 Acción o efecto de revolverse. 2. Cambio profundo, generalmente violento, en las estructuras políticas y socioeconómicas de una comunidad nacional (RAE, 2019).

16 Cabe una aclaración importante, esta cita de Rosa Luxemburgo fue omitida en las diferentes ediciones de la obra.

17 Aunque Freire va a profundizar la idea de revolución y de descolonización en Cartas a Guinea Bissau. Para el momento en que escribe Pedagogía del Oprimido ha leído de Fanon: Sociología de la Revolución (1959), Piel Negra Máscaras Blancas (1951) y Los Condenados de la Tierra (1961). Como así también a: Marcuse Razón y revolución (1953); Hegel, Fenomenología (1966); Gramsci El principe moderno y otras escrituras (1968); Memmi Retrato de un colonizado y La liberación del judio (1966); Sartre, Colonialismo y neocolonialismo (1965), Marxismo y Existencialismo (1968); Fromm, Miedo a la libertad, Corazón del hombre; Malcom X Autobiografía (1965); Mendel, Pour Decolonizer l'enfant, Sociopsicoanálisis de la autoridad; Althusser, La revolución teórica de Marx y de Fernández de Castro, Teoría sobre la revolución (1959). Cabe una aclaración, todas estas obras se encuentran en su biblioteca personal en el Instituto Paulo Freire con la firma del pedagogo y con fechas anteriores a la publicación de Pedagogía del Oprimido.

18 Texto que Freire lee en esos años y que hoy se conserva en su biblioteca del Instituto Paulo Freire, Sao Paulo. 
Inés Fernández Mouján. La idea de revolución en la Pedagogía del Oprimido

19 Recomiendo la lectura del artículo de Romão, José Eustáquio e Gadotti, Moacir, Paulo Freire e Amilcar Cabral. Razões Revolucionárias e a descolonização das mentes.

20 Término que Mao Tse Tung le otorga a la revolución china liderada por él en 1966; en un pie de página hace referencia a la obra del líder chino: "Ver Mao Tse Tung - "Sobre las contradicciones", Obras escogidas, volumen I, 1968" (Freire, 1971, p. 177).

21 La colonialidad es la persistencia de un patrón jerárquico y racial. Este término es acuñado por Aníbal Quijano en la tradición de pensadores negrxs para quienes el racismo es principio organizador de la acumulación de capital y de la modernidad: William Du Bois, Erick Williams, Frantz Fanon, Cedric Robinson, Kwame Nkrumah, Stuart Hall, entre otrxs; y de sus conversaciones con Immanuel Wallerstein. Señala Fanon en Los Condenados de la Tierra (1973): “(en) el contexto colonial, es evidente que lo que divide al mundo es primero el hecho de pertenecer o no a tal especie, a tal raza. En las colonias, la infraestructura es igualmente una superestructura. La causa es consecuencia: se es rico porque se es blanco, se es blanco porque se es rico" (p. 19).

22 La cursiva es mía.

\section{BY-NC-SA}

